\title{
The Development Characteristics of Adolescents' Responsibility and Educational Countermeasures
}

\author{
Xiaojuan Wei ${ }^{1, *}$ \\ ${ }^{1}$ School of Marxism, Shandong Youth University of Political Science, Ji'nan, Shandong 250103, China \\ "Corresponding author.Email: wxj@sdyu.edu.cn
}

\begin{abstract}
There are four main characteristics of adolescents' responsibility development, and there are the higher cognition and the lower behavior; the responsibility is related to age but there are ups and downs in high school period; there is a significant gender difference, and adolescents' responsibility is greatly affected by family factors. Thus, educators should guide the adolescents to know the subject value of responsibility, emphasize on practice than knowledge transferring, target different education to different gender and grade students, and cultivate adolescents' responsibility from cognition, emotion and action.
\end{abstract}

Keywords: adolescents, responsibility, characteristics, development, education

\section{INTRODUCTION}

Responsibility is an inevitable requirement for the survival of human groups. People always exist in a certain social relationship, so people living in society inevitably have to play various roles in social life and assume their responsibilities or obligations. Sense of Responsibility is an individual 's subjective cognition and experience of responsibility events (Li Ming, Geng Jinang, 2010), also known as responsibility awareness and responsibility (Ye Haosheng, Yang Wendeng, 2008), which refers to individuals' recognition of "things that should be undertaken by one's own social role" and "negligent consequences of things that should be done but not done" based on their roles and social requirements. Adolescents' sense of responsibility directly determine the future of a country and nation. In fact, responsible education, as a necessary way to train qualified citizens, has always been an important content of youth education in various countries. In the current era of rapid social change with multicultural conflicts and multiple values, moral indifference and lack of responsibility have become the universal problems that people of insight worry about. Therefore, it is significantly necessary to research on the cultivation of the adolescent responsibility.

\section{DEVELOPMENT OF CHARACTERISTICS OF ADOLESCENTS' RESPONSIBILITY}

\section{A. The higher cognition and the lower behavior}

Li Dan and his collogues (2012) used the storysituation method to study the development of children responsibility in grades 2-8, and found the low consistency existing between children's cognitive judgment and behavioral tendency. Our empirical research (2018) also found that adolescents' awareness of responsibility is better than their actual responsible performance. It can be seen that the development of adolescents' sense of responsibility has an abstract and macro-level tendency. The adolescents generally have a high level of sense of responsibility, but they cannot behave responsibly in specific field, especially in academic and the others self-field. Adolescents' awareness of responsibility is higher than that of responsible behavior, which intuitively reflects the phenomenon of "disjointed knowledge and action" in the youth development. The abstract, macro and "the inconsistency between knowledge and actions" characteristics of adolescents' responsibility development are related to the "knowing is easier than doing" feature of morality itself, as well as the adolescents' own psychological immaturity, such as weak will, and lack of self-control ability. The development characteristics reflects to a certain extent the current education model of moral education in schools is large and empty, which emphasizes knowledge transfer rather than moral practice. The education is separated from life practice and emphasizes on teaching rather than demonstration, which will no doubt lead to the imbalance between adolescents' responsibility awareness and responsibility behavior.

\section{B. Age related variation and ups and downs in high school period}

The basis of responsibility is individual cognition of the object of responsibility, so its development cannot be separated from the cognitive development related to 
individual maturity. A number of domestic and international empirical studies on responsibility have proven the importance of cognitive development for individual responsibility. The results of Sniras' research (2005) on the development of children moral skills show that children aged 13-15 have higher moral sensitivity and they are more tolerant and responsible, and show more responsible behavior compared with children aged 10-12. A study (Jing Xiaojuan, 2010) has found that the development of the concept of responsibility shows transition from concrete to abstract, from one-sided to comprehensive, and from other disciplines to self-discipline. Others (Cai Mei, et al., 2007) have found that senior high school students are significantly more mature than junior high school students in terms of the qualities of responsibility, such as independence and perseverance.

There is no doubt that there is a grade difference in adolescents' responsibility. However, the relationship between responsibility development and age (grade) is not entirely positive. In the 1990s, Shen Deli (1997) has found that second grade junior high school students in a "dangerous period", and their learning responsibility is lower than the other grade junior high school students. Tan Xiaohong (2008) also found that the overall level of responsibility of the second grade students in junior high school was lower than the other grade of junior high school. Xu Xianbin et al. (2010) has studied on the learning responsibility of junior high school students and found that the general development trend of responsibility is that as grades increase, junior high school students' responsibility does not rise but falls. Almost all the study finds that the lower responsibility level in the second grade junior high school students.

There is the same status of the second grade of high school students. Zhang Liangcai (2006) has studied the social responsibility of high school students, which shows that there is a difference in grades and the level of the second grade of high school students' social responsibility is lower. Zhao Xingkui (2008) has proved that there are significant grade differences in high school students' social responsibility, and the level of high school students' social responsibility is roughly ushaped. Thus, we can get a conclusion that adolescents' responsibility increasing with their age (grade) and it fluctuates in the second grades of junior and high school. All the teachers and parents should pay more attention to the "secondary phenomenon" of middle school students.

\section{Significant gender difference in adolescents' responsibility development}

There is a significant difference in female and male adolescents and the overall level of girls' responsibility is higher than boys'. This conclusion has been confirmed by the researchers. Wang Meiping's study
(2001) shows that the family responsibility of girls is higher than boys. Li Xue's study (2007) shows that boys are not as well as girls in terms of cognitive responsibilities and self-control abilities. Girls' strong sense of responsibility may be related to the psychological development characteristics and gender role characteristics of female groups. The physical and psychological development of girls is earlier than that of boys, and girls' physiology and psychology are more mature than boys of the same age, so they have a more mature understanding of roles and responsibility. In addition, girls are generally considered to be "obedient, kind, and compassionate", girls have received instructions and treatment that are deeply affected by the gender concept and have shown more gender traits under this social gender role expectation during the process of socialization. Girls show strong sense of responsibility and behave more responsibly under the influence of social gender role expectations and stereotypes.

\section{Adolescents' responsibility is greatly affected by family factors}

No one has questioned the effect of family on the development of individuals. In responsibility research field, it is also proved that parents is the more important factor than teachers and society (Zhang Yanyan,2010). Parenting style is an important family variable that affects children development. A study by Krebans \& Gibba (1996) shows that parenting styles have a significant positive predictive effect on children's empathy and altruistic behavior. It can also affect the development of responsibility. It is proved that authoritative parents have more care and understanding for children, whose children have more responsibility. Authoritarian parents interfere more with their children, and their children lack sense of social responsibility (Liu Chuang, 2007; Zhang Li, 2009) . Zhang Ning's (2012) research found that the sense of responsibility of high school students is significantly related to parenting styles. Autocratic, doting and neglecting parenting styles are significantly negatively related to individual responsibility and various responsibility related traits, for example, trust, encouragement and caring. Parenting style is significantly positively correlated with all factors of individual responsibility.

Moreover, the children number of family affect the development of responsibility. According to the results by Zhang Liangcai (2006) and Liu Wenying (2010), the adolescent growing in a single child family may get excessive care and love, he/she has little chance to practice by oneself and hardly be blamed by mistaken, so he/she can't understand the content and consequence of responsibility clearly. It is hard to take into account the others, and be responsible for his own behaviors. 


\section{EDUCATIONAL COUNTERMEASURES TO CULTIVATE THE ADOLESCENTS' RESPONSIBILITY}

In many significant historical events, young people in China show the strong sense of social responsibility, but in specific learning and other daily life events, the adolescents often show the phenomenon of lack of responsibility. For example, some students can't do their homework seriously and do not care about collective matter. Some students are irresponsible for their own actions, they are also indifferent to the others. Sometimes they know the responsibility correctly but their responsibility knowledge cannot by transformed into responsible behavior. Therefore, it is an important task to respect the dominant position of the adolescents and cultivate their responsibility according to the structure and development characteristics of responsibility.

\section{A. Guiding the adolescents to know the subject value of responsibility}

China has always defined human responsibility from the relationship between others and society because of collective culture, and put social responsibility at the top of all kinds of responsibility. Affected by historical tradition, our responsibility education has always shown a social orientation, and the cultivation of social responsibility is regarded as the biggest goal of responsibility education. Thus many young people know the importance of social and family responsibility and ignore the self-responsibility. Even though, there are a lot of teenagers can't realize the importance of self-responsibility.

Responsibility has always been an crucial issue related to social continuity and national development. Any country, any person should pay attention to civil responsibility at any time. We believe that there is nothing wrong with strengthening the responsibility itself. However, while emphasizing the social orientation of responsibility, we cannot ignore the importance of responsibility for individual growth and development. A person who cannot be responsible for himself/herself is likely to become an unpopular person who cannot complete tasks on time and does not keep his promises. This person may also develop into bad behavior or even walk on the path of crime. Establishing the principal value concept of responsibility, parents will be more aware of the importance of responsibility for their children's future and pay more attention to the cultivation of children responsibility. The principal value concept of responsibility also require us to guide the adolescents understand that responsibility is not only the social and moral requirements by society and teachers, but also crucial to his own future. Only a person who knows it is himself/herself as the subject of responsibility, he/she can actively participate in education and try to be a good student, a good partner and a qualified citizen.

\section{B. Emphasizing on responsibility practice besides knowledge transfer}

Life experience tells us that many adolescents know the norms and guidelines, and they know what to do, but their actual behaviors lag behind the awareness of responsibility, thus showing the characteristic of "disjointed knowledge and action". This also shows both the effective and ineffective school responsibility education. It is said to be effective because the adolescents know what ought to do and what should not be done through school education, and they get clear criteria for judging right and wrong. Therefore, whether they do this or not, the adolescents tend to evaluate their behavior better than the actual. It is said to be ineffective because the adolescents lack actual action, although they know which behaviors are affirmed and unaccepted. Too high and unrealistic evaluation of one's own behavior is itself a kind of irresponsible behavior. The reason is that school moral education has always too much focused on knowledge teaching. In addition, although some teachers are engaged in the teaching and educating profession, they sometimes behave irresponsibly and set bad examples of "all mouth and no trousers" to students, which have caused some students mere talk and no action. Therefore, to strengthen the responsibility education, we must rationally examine and dialectically view the effect of school moral education, stimulate responsibility emotion, strengthen moral education practice, and make responsibility education come from life and apply to life.

\section{Paying attention to the group differences, and target education to girls and junior high school students}

Gender difference has been confirmed in the research of developmental psychology. Responsibility education should especially care about boys and strengthen the guidance based on the difference between male and female. In addition, responsibility education should be designed and acted according to the different grade of students, for example, the emphasis on the habit of doing homework on time and developing a good life habit in the primary school, the focus on the social role cognition and developing the responsibility identity in the high school.

Furthermore, because of "secondary phenomenon", we must pay attention to the students in the middle grades of high school, and let them live in the atmosphere of responsibility since they entered the new school. Teachers and parents should try to understand and respect the secondary grade students, encouraging them to make decision by themselves and motivating their achievement motivation. 


\section{Cultivating adolescents' responsibility from three aspects of cognition, emotion and action}

As an important psychological quality of the individual, responsibility includes three components: responsibility cognition, responsibility emotion and responsibility behavior. Thus educators need to treat adolescents as the independent individuals and the subject of responsibility generation. It is necessary to cultivate the responsibility by enhancing responsibility awareness, stimulating responsibility emotions, and increasing responsibility practice according to the psychological structure of responsibility.

First, take measures to guide the adolescents form responsibility awareness. Responsibility cognition is the basis of responsibility education. Only a person know what is responsibility and what is the consequence of irresponsibility, he can think and behave responsibly. The educators should help the adolescents get responsibility knowledge by different ways, such as class meetings, classroom teaching and topic lectures, and develop the adolescents judgment and reasoning ability by group discussions and debates.

Second, cultivate the adolescents responsibility emotion. Psychology tells us that there are many factors working in the process of responsible behavior, such as motivation, will and emotion. We have enough responsibility cognition, which doesn't mean that we can behave responsibly. As the internal drive of behavior, emotion can stimulate and induce the generation of individual responsible behavior. Therefore, the educator must pay attention to the cultivation of the adolescents' empathy and compassion, using the art of language to let the adolescents gain emotional experience.

Third, give the adolescents opportunity to act and practice. Cultivation of responsibility awareness is a question of obtaining cognition and emotion from the perspective of psychology, and its formation education must conform to the relevant laws of education and be carried out in life practice. Therefore, for schools, it is necessary to actively create the conditions and atmosphere for students to practice responsibility awareness, and to improve students' sense of responsibility and emotion through different methods such as class hygiene cleaning, campus voluntary labor, and various forms of social practice. Cultivate their capacity for responsible behavior in participation. It is recommended that the school should provide each student with an equal space for development. By allowing students to take turns as class cadres or take charge of a specific matter, each student has the opportunity to participate in collective activities and class management. For parents, they should first at all be responsible, setting responsible examples for children, and let children do their own things in daily life, such as packing their schoolbags, cleaning rooms and organizing a friend party, thus generating their sense of responsibility in life practice.

\section{CONCLUSION}

Due to the significance of adolescent responsibility, we should carry on the responsibility education according to the four main characteristics of adolescents' responsibility development. Establishing the concept of the subject, both teachers and parents guide the adolescents to know the subject value of responsibility, emphasize on practice besides knowledge transferring, implement different education to different gender and grade students, cultivate adolescents' responsibility from cognition formation, emotion stimulating and action practice.

\section{References}

[1] Li Ming and Geng Jinang, "A socio-cultural Psychological Analysis of Responsibility", Journal of Nanjing Normal University, pp. 111-115, March 2010. (In Chinese)

[2] Ye Haosheng and Yang Wendeng, "On the Duality of Responsibility and the Cultivation of the Sense of Responsibility - From the Perspective of Psychology", Psychological Exploration, pp. 9-13, June2008. (In Chinese)

[3] Li Dan, Huang Qiangwei and Ding Xuechen, "Responsibility Development of Children in Grade $2 \sim 8 "$, Studies of Psychology and Behavior, pp. 347-354, October, 2012. (In Chinese)

[4] Sniras S and Malinauskas R, "Moral Skills of School Children", Social Behavior \& Personality An International Journal, pp. 383-390, April 2005

[5] Jing Xiaojuan and Jing Xiaoqiang, "Research on the Free Descriptions of the Concept of Responsibility Given by Children of $7 \sim 12$ in Beijing", Theory and Practice of Education, pp. 59-62, Feburary, 2010. (In Chinese)

[6] Cai Mei, Liu Su and Lei Xiuya, "The Development and Evaluation of Children Responsiblity",Journal of HuBei TV University, pp. 140-141, September, 2014. (In Chinese)

[7] Tan Xiaohong and Huang Xiting. "A Preliminary Study of the Characteristics of Chinese Middle School Students' Responsibility", Journal of Southwest University, pp. 45-48, May, 2008. (In Chinese)

[8] Xu Yuling, "A study of Junior High School Students' Collective Responsibility", unpublished.

[9] Xu Xianbin and Shao Guojun, "Investigation on Learning Responsibility of Junior High School Students", Educational Measurement and Evaluation, pp. 41-44, Febuary, 2010. (In Chinese)

[10] Zhang Liangcai and Sun Jihong, "An Investigation on High School Students' Sense of Responsibility in Shandong Province", Journal of Educational Studies, pp. 82-90, Agust, 2006. (In Chinese)

[11] Wang Meiping, "Adolescents'Sense of family obligation in Urban and Rural Areas" ,Psychology Development and Education, pp. 28-32,June2001. (In Chinese)

[12] Li Xue, "A Study on the Characteristics of the Middle Schoo Students' Social Responsibility",Chinese Journal of School Health, pp. 32-33, January, 2007. (In Chinese) 
[13] Krevans, J. C. and Gibbs. "Parents' Use of Inductive Discipline: Relations to Children's Empathy and Prosocial Behavior", Child Development, vol. 67, pp. 3263-3277. March, 2007.

[14] Liu Chuang and Yang Lizhu, "Research into the Relationship between Parental Rearing Patterns and Development of $3 \sim 6$ Years Children's Sense of Responsibility", Studies in Early Childhood Education, pp. 56-59, January, 2017. (In Chinese)

[15] Zhang Li, Mao Jinping and Zhang Suxian, "Relationship between Responsibility and Parenting Rearing Pattern of High School Students", China Journal of Health psychology, pp. 1362-1365, November, 2009. (In Chinese)

[16] Zhang Ning, "Relationship between Parenting Style, Responsibility and Prosocial Behavior of High School Students", unpublished.

[17] Liu Wenying, "The Development and Usage of Responsibility Questionnaire in Grade 7-12", unpublished.

[18] Shen Deli, Theory and Practice of Non-intelligence Factors, Beijing: Educational science Publishing House, 1997. (In Chinese) 